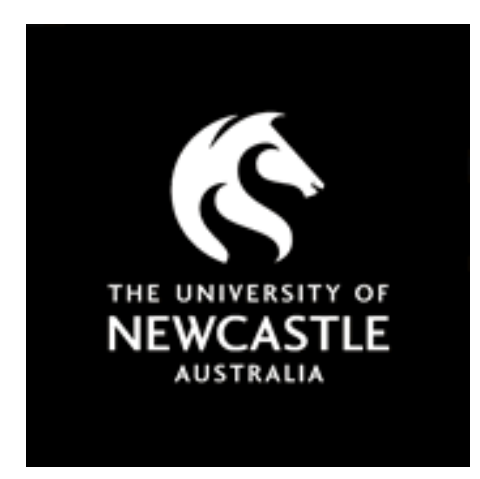

NOVA

University of Newcastle Research Online

nova.newcastle.edu.au

Magnuson, Bryce; Reimers, Vaughan; Chao, Fred. "Re-visiting an old topic with a new approach: the case of ethical clothing", Published in the Journal of Fashion Marketing and Management: an International Journal Vol. 21, Issue 3, p. 400-418. (2017)

Available from: http://dx.doi.org/10.1108/JFMM-10-2016-0091

Accessed from: http://hdl.handle.net/1959.13/1351345 


\title{
Re-visiting an old topic with a new approach: the case of ethical clothing
}

\begin{abstract}
Purpose - A recent study by Reimers et al. (2016) suggests that the attitude-behaviour gap, as it applies to ethical clothing, may be due to academics having defined it differently to the way that consumers do. This study serves as a direct follow-up to that study by employing their consumer-based definition in order to help identify the clothing attributes that influence the purchase of ethical clothing .
\end{abstract}

Design / methodology / approach - A consumer household sample in combination with a quantitative survey approach was used to collect the data, while structural equation modelling was used to analyse it.

Findings - In spite of the ethical clothing context, only two of the four ethical clothing dimensions were found to influence consumer attitudes. In contrast, all three conventional dimensions were found to be significant.

Originality / value - Ethical clothing has typically been operationalised using just two of these four dimensions. Ironically, one of the two dimensions often overlooked by academics, slow fashion, had one of the strongest influences on consumer attitudes. In addition, the cost of buying ethical clothing has often been defined in unidimensional terms; typically price. This study adopted a broader conceptualisation, defining it in terms of price, time and effort, and found it to serve as a salient influence over consumers' attitudes to ethical clothing.

Key words Clothing industry, Clothing, Ethics, Fashion, Social responsibility. Paper type Research paper 


\section{INTRODUCTION}

Climate change, pollution and the over-use of pesticides all pose a major threat to life on this planet. In addition to environmental degradation, there is also the problem of resource depletion (NASA, 2013). Whilst the clothing industry makes a major contribution to the global economy via the trade, income and employment it generates (MacCarthy \& Jayarathne, 2011), these benefits can come at a great cost. The clothing industry contributes to environmental degradation via the pollution it generates and the many natural resources it consumes. Moreover, its negative impacts extend beyond the environment in general, to include direct impacts on humans and animals specifically. In the case of the former, industry practices in some developing nations often result in labour violations (Jägel et al., 2012), while in the case of the latter, many animals suffer via damage to their habitats and the use of their fur or skin as clothing materials (Choose Cruelty Free, 2014). Further compounding these problems is fast fashion. By encouraging the increased consumption of clothing, fast fashion magnifies the fashion industry's negative impact on resource consumption and pollution, and the welfare of clothing employees and animals.

As such, the clothing industry exerts four types of negative impact. Three of these are direct in the form of the harm it can cause to the environment, employees and animals, and in the case of the fourth - fast fashion - by exacerbating the industry's negative impact on each of these areas. In response, some clothing manufacturers and retailers have introduced ethical clothing (also referred to as socially responsible clothing). Ethical clothing seeks to minimise each of the aforementioned negative impacts. For example, it is environmentally responsible in that it is made from natural materials such as cotton, hemp and bamboo, and is made without the use of pesticides and chemical fertilizers. Ethical clothing firms also adopt codes of practice relating to issues that affect employee (Goworek, 2011) and animal welfare (Choose Cruelty Free, 2014). In order to address the problems associated with fast fashion, some producers have countered with slow fashion. Slow fashion seeks to reduce the level of clothing production and disposal by increasing the longevity of clothing via the creation of well-made, seasonless garments (Watson \& Yan, 2013).

Unfortunately, ethical clothing has not yet been the success that many hoped it would be. Whilst research has often reported positive consumer attitudes' towards ethical clothing, such attitudes have often failed to translate into actual purchase. As a result, sales of ethical clothing continue to account for a relatively small percentage of overall clothing sales (Chan \& Wong, 2012). This discrepancy between consumer attitudes and actual purchase behaviour is referred to as an attitude-behaviour gap (Carrington et al., 2010).

One likely explanation for the attitude-behaviour gap is the way academics have measured consumer attitudes towards ethical clothing. A recent study by Reimers et al. (2016) found that whereas previous research had measured consumer attitudes using just one, two or three dimensions, consumers actually define ethical clothing using four: environmentally responsible, employee welfare, animal welfare and slow fashion. Their findings suggest that academic research to date may have measured consumers' attitudes in ways that differ from the purchase criteria they actually use. More specifically, past research typically regarded clothing as 'ethical' if it sought to minimise the negative impact it has on the environment and the employees who made it. However, based on the findings by Reimers and colleagues, consumers may actually regard this same item of clothing as being less than ethical if it was produced in a way that harms animals and is non-durable in terms of quality and/or fashionability.

As a result, previous research has failed to utilise all potentially salient attributes when measuring consumer attitudes towards ethical clothing. When this occurs, the influence of those attributes that were included is likely to be overstated, whilst at the same time understating the importance of those attributes that were ignored (Hair et al., 2010). 
Moreover, the utilization of a less than inclusive definition means that the influence of those dimensions that were included could not be measured relative to those dimensions that were overlooked. This inability to determine the relative influence of the four dimensions of ethical clothing not only applies to its ethical aspects, but its conventional ones as well. Research has found that consumers not only evaluate ethical clothing on both its conventional and ethical attributes, but that the former can often take precedence over the latter (i.e. Jägel et al., 2012; Jegethesan et al., 2012; Koszewska, 2013; Moon et al., 2013; Ogle et al., 2014). However this body of research also suffers from the use of a less than inclusive operationalisation of ethical clothing, meaning that while it has been established that conventional attributes are often more salient than ethical ones, this finding relates to some, but not all, ethical attributes. This further reinforces the notion that the test attributes given to consumers in previous studies may differ from the actual set they use in reality. In light of the attitude-behaviour gap, this serves as an important source of concern.

This study will seek to address this problem using the four-dimension operationalisation of ethical clothing empirically developed by Reimers et al. (2016). However, whereas that study measured the influence of these four dimensions on consumer beliefs about the meaning of ethical clothing, this study will measure their influence on consumers' purchase attitudes towards ethical clothing. The rest of this paper is structured as follows. First a review of the literature provides insight into the attributes that influence the purchase of ethical clothing. This is followed by a discussion of the methodology, the presentation of the results and suggestions for further research.

\section{REVIEW OF THE LITERATURE}

The attributes that comprise a garment of clothing play a key role in influencing purchase behaviour because they serve as the criteria consumers use to evaluate it (Rahman et al., 2008). Moreover, because consumers' evaluate clothing using multiple metrics (AbrahamMurali \& Littrell, 1995; Swinker \& Hines, 2006), the key to marketing success lies in determining those attributes that are most important to consumers (Forney et al., 2005). In the specific context of ethical clothing, environmentally responsible attributes, employee welfare attributes, animal welfare attributes and slow fashion attributes all serve as potentially salient influences.

Identifying the relative influence of each of these four dimensions is important because, to the authors' best knowledge, this is the first study of its kind to utilise this operationalisation when measuring consumer attitudes towards ethical clothing. As such, the individual influence of each of these dimensions on consumer attitudes has yet to be determined. This serves as a significant knowledge gap because the importance consumers assign to the various features that comprise an ethical garment varies on a dimension-by-dimension basis (Hwang et al., 2015).

However, because ethical attributes are just one set of attributes that consumers' consider when evaluating ethical clothing (Sneddon et al., 2014), conventional clothing attributes must also be included. In focusing on the ethical aspects of their clothing, many ethical clothing firms may have overlooked the important role that conventional attributes play in influencing purchase. With the exception of only the most highly-involved ethical consumers, ethical attributes are only likely to be perceived as providing value if the garment as a whole performs at least as well as conventional alternatives (Meyer, 2001).

The conventional attributes that comprise a garment of clothing can be classified into three categories - physical attributes, extrinsic attributes and cost attributes (i.e. Kim et al., 2002; Zhang et al., 2002). Physical attributes refer to the tangible qualities of the garment itself and include such attributes as durability, colour, style and size. Extrinsic attributes refer to a garment's non-tangible attributes and include brand name, country of origin and the image of 
the store selling it. Cost, as the name indicates, refers to the cost of obtaining the garment; something that extends beyond its financial cost (i.e. price) to include time and effort as well.

The approach of this study is based on the notion that clothing attributes influence a consumer's overall attitude towards a garment of clothing, which then in turn influences their purchase intention. These clothing attributes comprise four ethical dimensions and three conventional ones. Each of these dimensions will be discussed in turn, beginning with environmentally responsible attributes.

\section{Environmentally Responsible Attributes}

Environmentally responsible attributes are designed to address the negative environmental impacts of the clothing industry. A garment of clothing is regarded as being environmentally responsible if it is made from natural fibres, made without the use of pesticides, made in the most efficient way possible and made in a way that does not otherwise harm the environment (Chan \& Wong, 2012; Gam et al., 2014). Provided that no harmful pesticides are involved, natural fibres are considered to be more environmentally responsible than synthetic fibres because unlike the latter, they do not utilise non-renewable resources (Hansen \& Schaltegger, 2013). Moreover, a garment made from natural fibres is biodegradable due to the absence of chemicals (Afrin et al., 2009). In contrast, not only are synthetic fabrics typically manufactured using non-renewable resources (e.g. oil), they also often utilise harmful chemicals throughout their production (Scaturro, 2008). This can lead to air pollution and the emission of greenhouse gases (Saicheua et al., 2012) and heavy metal substances (Laursen et al., 2007).

The importance consumers assign to environmentally responsible clothing is closely linked to their environmental concern (Gam, 2011). As consumers have become better educated about the environment and developed a greater level of concern relating to it, their consumption patterns have changed accordingly. This can often result in clothing's environmentally responsible attributes taking on a more salient influence (Koszewska, 2013). The findings from empirical research add support to this notion. Studies consistently report that environmentally responsible attributes influence consumers' attitudes and/or purchase intentions towards ethical clothing (i.e. Gam, 2011; Gam et al., 2014; Hwang et al., 2015; Shen et al., 2012). For example, Jägel et al., (2012) asked respondents to identify the three most important features that ethical clothing should possess. Amongst their top-10 answers were such attributes as made from natural materials (ranked $1^{\text {st }}$ ), produced in an environmentally friendly way $\left(4^{\text {th }}\right)$ and recycled $\left(10^{\text {th }}\right)$. These findings in combination lead to the following hypothesis:

Hypothesis 1: Environmentally responsible attributes influence consumers' overall attitude towards ethical clothing.

\section{Employee Welfare Attributes}

Employee welfare attributes are designed to address the negative impacts that may be experienced by those working in the clothing industry. These impacts are typically associated with clothing sweatshops, and are reflected in such attributes as fair wages, fair working conditions, and the non-use of child labour (Shen et al., 2012). These attributes provide consumers with the option to help improve the livelihood of clothing employees via the purchases they make.

Increasing consumer awareness of employee welfare issues has often resulted in consumer concern in relation to Fair Trade issues and worker's rights (Jung \& Jin, 2014). This concern can then motivate consumers to seek out clothing that did not exploit those involved in its production (Sneddon et al., 2014). These consumers not only feel a responsibility to society; they express this sense of responsibility via their ethical purchases (Carrington et al., 2010). 
Employee working conditions can therefore serve as a key assessment criterion for consumers (Ogle et al., 2014).

In support of such a notion, research has consistently found that employee welfare attributes influence consumer attitudes and purchase intentions towards clothing (Gam et al., 2014; Hwang et al., 2015; Kim et al., 2013; Kozar \& Hiller Connell, 2013; Shen et al., 2012). For example, Jägel et al. (2012) found that fair wages (ranked $3^{\text {rd }}$ ) and fair working conditions $\left(8^{\text {th }}\right)$ ranked amongst consumers top-10 criteria when assessing ethical clothing. Sneddon et al. (2014) measured consumer attitudes towards employee welfare when buying clothing made from wool; a context usually associated with animal welfare. Even in this specific context, consumers still reported that their attitudes were influenced by employee welfare attributes. It is findings such as this that lead to the following hypothesis:

Hypothesis 2: Employee welfare attributes influence consumers' overall attitude towards ethical clothing.

\section{Animal Welfare Attributes}

Animal welfare attributes are designed to minimise any negative impacts the clothing industry may have on animals. These typically take the form of dyes and chemicals being tested on animals, or animals being killed in order to derive fur or leather. Due in part to the marketing efforts of animal welfare groups, consumers' are now more aware of the impacts the clothing industry can have on animals (Auger et al., 2003). As a result, a growing number of consumers are using animal welfare attributes to help guide their purchase decisions (Jägel et al., 2012).

Yet in spite of this, there is a relative dearth of empirical research relating to the influence of animal welfare attributes on consumer attitudes. A likely explanation for this is that academic efforts to conceptualise and/or operationalise ethical clothing have often overlooked it. However the findings from those studies that did include it support the notion that it does influence consumer attitudes and/or purchase intentions (i.e. Sneddon et al., 2014). For example, Hustvedt et al. (2008) found that $19 \%$ of their sample bought wool clothing on the basis of its animal-friendly attributes. Ogle and colleagues (2014) reported an even larger segment of animal-sympathetic consumers, with almost half their sample giving consideration to the treatment of animals when buying clothing. These findings in combination lead to the following hypothesis:

Hypothesis 3: Animal welfare attributes influence consumers' overall attitude towards ethical clothing.

\section{Slow Fashion Attributes}

Slow fashion essentially represents a shift in clothing consumption from quantity to quality. By employing quality-oriented production methods and fewer fashion cycles, slow fashion seeks to encourage consumers to buy fewer garments but of a higher quality, and to wear them for a longer period of time. Attributes that align with the ideals of slow fashion include a longer usable life in terms of both fashionable longevity and physical durability. As such, consumers who value slow fashion will avoid garments made of poor quality, that will fail to withstand the effects of laundering and/or that will soon be out of fashion (Jung \& Jin, 2014; Watson \& Yan, 2013). By buying high quality, fashionably versatile garments, consumers are encouraged to hold onto them for longer. This, at least in theory, minimises the need for replenishing purchases and the subsequent drain this has on the environment. For this reason, individuals who value slow fashion are considered to be conscientious consumers concerned about the impacts of their clothing purchases (Pookulangara \& Shephard, 2013). 
In confirmation of its potential importance, research has found that slow fashion attributes do in fact influence consumers' purchase intentions (Jung \& Jin, 2014; Niinimäki, 2010). For example, when Jägel et al (2012) asked respondents to identify the most important features that ethical clothing should possess, they found that the durability of the garment served as the second most frequently cited response. Similarly, Watson and Yan (2013) found that slow fashion consumers derive their satisfaction from attributes such as high quality, longlasting and versatile. Based on these findings, the following hypothesis is proposed:

Hypothesis 4: Slow fashion attributes influence consumers' overall attitude towards ethical clothing.

Cost

This study defines cost as the barriers encountered in the undertaking of a shopping activity. When shopping, the consumer must contend with three fundamental costs: time, effort and money (Seiders et al., 2007). Cost is particularly relevant in the context of ethical clothing because consumers must often incur greater costs in order to behave in an ethical manner (Laroche et al., 2001). Not only is ethical clothing less widely available, it is usually more expensive. This translates into higher search, travel and monetary costs (Ellis et al., 2012). These three costs in combination serve as a plausible explanation for the limited success of ethical clothing, because consistent with the fundamental marketing principle of value exchange, the cost of ethical consumption may exceed its perceived benefits (Ottman et al., 2006).

Yet in spite of this, academic studies have often focused on isolated cost attributes, most typically, monetary costs. Empirical research has found that price has a key influence on the purchase of ethical clothing (i.e. Gam, 2011; Jägel et al., 2012). Consumer skepticism over firms' ethical claims can lead to the perception that ethical products are too expensive (Bonini \& Oppenheim, 2008). While there is research to suggest that consumers are prepared to pay more for ethical clothing (i.e. Shen et al., 2012), such findings must be put into perspective. Whereas the cost of ethical clothing is often relatively high, the premium respondents are prepared to pay is often far less (McGoldrick \& Freestone, 2008). For example, using an experimental auction method, Ellis et al. (2012) found that just $12 \%$ of respondents were prepared to pay more than $\$ 5$ extra for an organically produced cotton tshirt, with $26 \%$ not willing to pay any premium at all. Peterson et al. (2012) reported a similar finding, with their respondents only willing to pay an extra $\$ 0.20$ for woolen gloves characterised by their environmentally responsible and animal welfare attributes.

The widespread availability of ethical fashion brands is also considered to be crucial to their success because otherwise the added search costs serve as a key source of inconvenience (Joergens, 2006). In support of this, Perry and Chung (2016) found that too much time and effort in locating and accessing ethical clothing served as a key reason for consumers' not to buy it.

While much of the research into the influence of cost has examined price and convenience (e.g. time and effort) independently, Laroche and colleagues (2001) studied them together. They found that as the perceived inconvenience of buying ethical products increased, consumer willingness to pay a higher price for them decreased. Carrigan and Attalla (2001) found that respondents were selectively ethical in that ethical purchases only occurred if the item did not cost too much in terms of price and search effort. These findings, in combination, lead to the following hypothesis:

Hypothesis 5: As consumer perceptions of cost increase, their overall attitude towards ethical clothing becomes less positive. 


\section{Physical Attributes}

The physical attributes of an item of clothing pertain to its tangible qualities and therefore include such attributes as fit, comfort, aesthetic appeal and colour (Abraham-Murali \& Littrell, 1995). These attributes often serve as consumers' most important evaluative criterion when it comes to conventional clothing (Taylor \& Cosenza, 2002; Zhang et al., 2002). The same also applies to ethical clothing, with research often revealing that consumers consider physical attributes to be more important than ethical attributes (Joergens, 2006; Niinimäki, 2010; Pookulangara \& Shephard, 2013). For example, when Jägel et al. (2012) asked respondents to identify the most important features ethical clothing should possess, comfort and fit $\left(5^{\text {th }}\right)$ and style $\left(6^{\text {th }}\right)$ ranked above fair working conditions and recycled.

Findings such as these have led academics to conclude that consumers will only buy ethical clothing if its' quality and appearance is comparable to that of conventional clothing (Niinimäki, 2010). A likely reason behind the importance of physical attributes in an ethical clothing context is the consumer perception that it is of inferior quality (Meyer, 2001). In such a circumstance, physical attributes can serve as the determining factor in either confirming or allaying such concerns. This notion leads to the following hypothesis:

Hypothesis 6: Physical attributes influence consumers' overall attitude towards ethical clothing.

\section{Extrinsic Attributes}

The extrinsic attributes of a garment represent its non-tangible aspects and include its brand name, country of origin and the image of the retailer that sells it (Abraham-Murali \& Littrell, 1995; Jin et al., 2010). The clothing one wears serves as a key means of status display and self-expression (Kim \& Damhorst, 1999). In this context, the image-oriented nature of extrinsic attributes plays a key role in establishing the status associated with a garment, and in distinguishing it from competing garments. They can also facilitate the consumer decisionmaking process. Less experienced shoppers or those unfamiliar with a particular product category may utilise brand image, store image or country of origin as a pseudo measure of quality (Jin et al., 2010). For these reasons, extrinsic attributes can serve as a key influence over consumers' attitudes and behaviours (Taylor \& Cosenza, 2002).

In support of this, research has found that extrinsic attributes not only exert a salient influence in an ethical clothing context (Sneddon et al., 2014) but also that attributes such as brand image can relegate ethical attributes to the role of secondary consideration (Carrigan \& Attalla, 2001). For example, Jegethesan and colleagues (2012) found that consumers ranked brand name and country of origin ahead of ethical dimensions such as employee welfare, animal welfare and environmental attributes. In fact, such is the importance of branding that it has been suggested that a key barrier to the purchase of ethical products may be consumers existing brand loyalty to conventional brands (Bray et al., 2011). These findings in combination lead to the following hypothesis:

Hypothesis 7: Extrinsic attributes influence consumers' overall attitude towards ethical clothing.

\section{Overall Attitude and Purchase Intention}

A consumer's overall attitude reflects their personal evaluation of an attitude object, typically resulting in a favourable or unfavourable response towards it (Kim et al., 2002). In a clothing context, the focus of this evaluation is on the garment's various attributes as these are fundamental to consumers' purchase decision (Hyllegard et al., 2009). This study proposes that consumers' evaluate seven dimensions of ethical clothing; four of them ethical in the form of environmentally responsible, employee welfare, animal welfare and slow fashion attributes, and the other three conventional, in the form of cost, physical and extrinsic 
attributes. This evaluation then results in an overall attitude towards a garment, which then in turn influences consumers purchase intention. The logic behind the latter relationship rests on the notion that overall attitudes essentially serve as the final consideration preceding purchase intention (Zhang et al., 2002). With empirical research consistently supporting the notion that consumers' overall attitude towards ethical clothing determines their purchase intention towards it (Hwang et al., 2015; Ogle et al., 2014) the following hypothesis is proposed:

Hypothesis 8: Consumers' overall attitude towards the various attributes of ethical clothing will influence their purchase intention towards it.

The relationship between the nine constructs under study is visually depicted in the conceptual framework in Figure 1.

Figure 1. Conceptual framework - The purchase determinants of ethical clothing

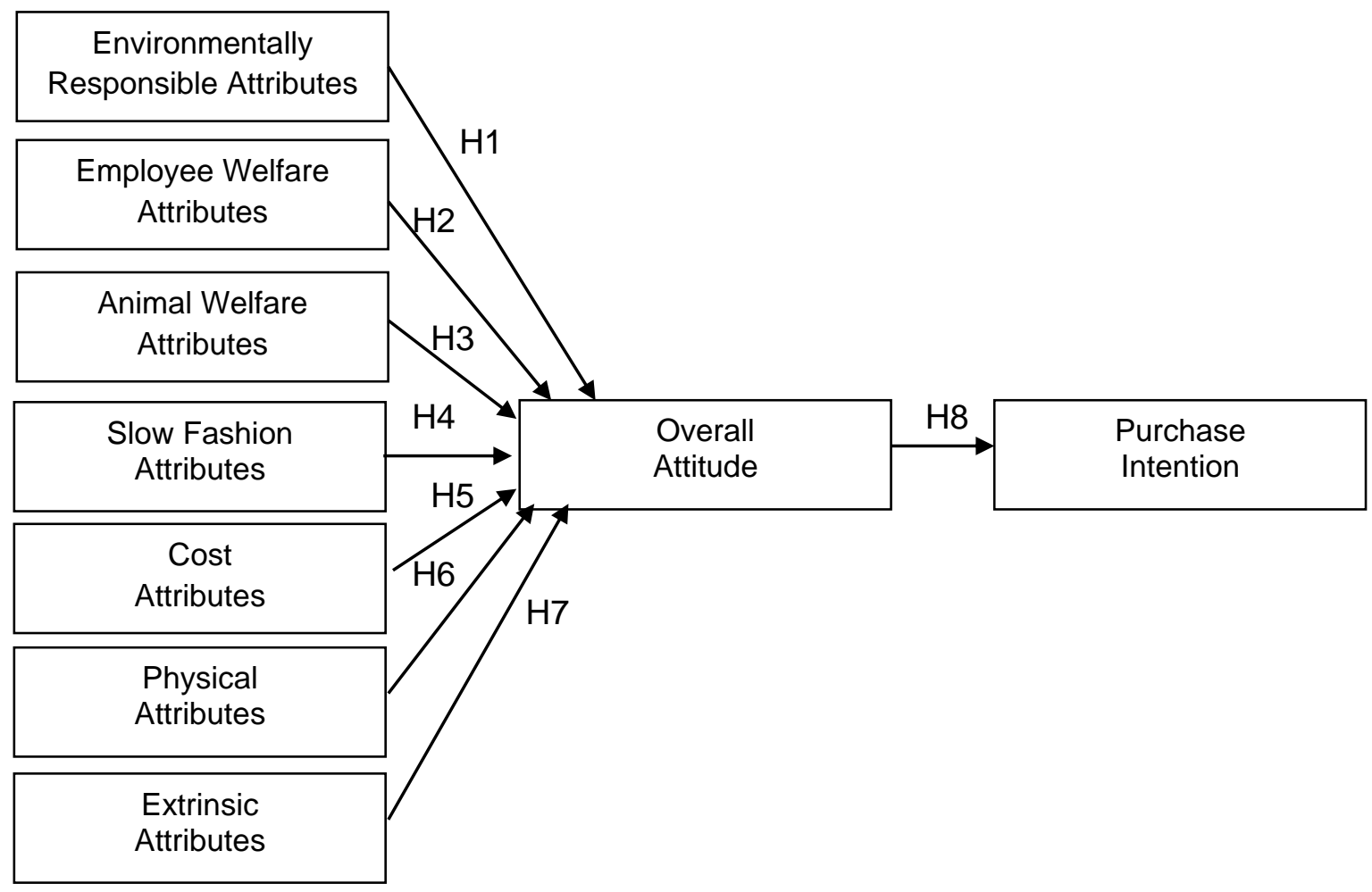

\section{METHODOLOGY}

Attitude context

In order to find a high correlation between attitude and behaviour, the attitude has to be measured towards that specific behaviour (Kollmuss \& Agyeman, 2002). This requirement necessitates specifying an attitude context which then serves as a frame of reference for respondents. Casual wear was chosen as the attitude context for this study. Casual wear describes informal clothing that is suitable for everyday wear rather than formal occasions (Oxford Dictionary, 2017). It was chosen as the attitude context because it serves as a familiar clothing category for most consumers (Zhang et al., 2002), and because many fashion outlets that stock ethical clothing tend to concentrate on casual wear (Beard, 2008). In order to provide an example that would not exclude a large proportion of potential respondents due to age, gender or fashion preference (such as a T-shirt, shorts or jeans may do) the generic term 'shirt' was used as the casual wear example given to respondents. 


\section{Measures}

Responses for six of the seven independent variables were measured on a 7 -point scale (1 $=$ not at all important, 7 = extremely important). The same scale items used by Reimers et al. (2016) to measure the four ethical dimensions - environmentally responsible, employee welfare, animal welfare and slow fashion - were also employed in this study. The scales used to measure physical and extrinsic attributes were adapted from existing scales (i.e. Abraham-Murali \& Littrell, 1995; Jin et al., 2010), as were the variables overall attitude and purchase intention (i.e. Hustvedt \& Dickson, 2009).

However, in the case of cost attributes, it was necessary to develop a new scale. Many of the studies that have investigated the influence of cost have been qualitative, whilst the few cost-based quantitative studies that have been conducted have often focused solely on price (i.e. Ellis et al., 2012; McGoldrick \& Freeman, 2008; Shen et al., 2012). A combined focus on both monetary and non-monetary costs is particularly important in the case of ethical clothing because it is often characterised by its higher price and limited availability (Beard, 2008). Based on its conceptualisation as the monetary, time and effort barriers encountered in the purchase of ethical clothing, cost was operationalised using the following scale items:

- It costs about $25 \%$ more than garments that look similar to this one, but that don't possess all of its same qualities (e.g. made without pesticides, not made in a sweatshop etc.).

- It takes approximately 20 minutes travel time to reach the nearest store selling this type of garment.

- Because this sort of garment isn't widely available, extra time and effort is required to identify stores that sell it.

- In general, buying this type of garment is not as convenient as buying a more 'conventional' garment.

\section{Sampling}

The population for this study was defined as adults (e.g. aged 18 years or older), who buy their own clothing, and that reside in a regional city in south-east Australia. The decision to choose a single township as the sampling frame was based on the specific way in which the cost construct was operationalised. One of its scale items referred to a specific time-cost associated with the purchase of ethical clothing (i.e. it takes approximately 20 minutes travel time to reach the nearest store selling this type of garment). This specific operationalisation was chosen because it reflected the actual time involved in travelling from the township under study to the nearest retail centre that sells ethical clothing. This specific measure was adopted on the assumption that an attitude based on actual travel time would provide more accurate insight into consumers' attitude. Because this same measure did not apply to any other travel/retail context in the region, applying it to multiple towns risked compromising the validity of this scale item.

A combination of systematic and stratified sampling was used to draw the sample. More specifically, under this two-step method of sampling, both the neighbourhoods and the household starting point within each of those neighbourhoods were randomly selected. Once the starting point within each of these strata had been selected, every fourth household received a survey package comprising a cover letter, questionnaire and reply-paid envelope. Of the 1500 questionnaires delivered in this way, 299 usable surveys were completed, resulting in an effective response rate of $19.9 \%$.

An analysis of gender, age and education was used to determine the extent to which the sample could be regarded as an accurate representation of its population. For gender, females were slightly over represented, accounting for $61 \%$ of respondents, whereas they account for just $51 \%$ of the population (Australian Bureau of Statistics, 2011). However a likely explanation that may limit the extent to which this can be regarded a limitation is that 
the survey was specifically directed to an occupant that shopped for and bought their own clothing. Given that women are the more likely of the two genders to do so (Holland, 2015) it is a logical outcome that the sample would comprise a majority of women.

In terms of age, the sample served as a fairly accurate representation of its population with the one exception being the 45-59 age category, which was over-represented (accounting for $39 \%$ of respondents) relative to the population (28\%). In terms of education, the sample accurately portrayed the population across all three categories: high school, vocational and university (Australian Bureau of Statistics, 2011).

\section{ANALYSIS}

\section{Reliability and validity}

All scales were subject to exploratory factor analysis (EFA) and confirmatory factor analysis (CFA). EFA is typically used to provide a clearer interpretation of the data by reducing the focus of analysis from a larger number of individual scale items to a more manageable number of latent constructs (Crowley and Fan, 1997). It was specifically employed in this study due to the fact that some of the scale items used to operationalise the constructs were new or modified (Gorsuch, 1997). The EFA revealed that all scales employed in this study have a unidimensional structure.

CFA serves as the next step after EFA. Whereas EFA is used to explore the factor structure of the data, CFA is used to confirm it (Crowley and Fan, 1997) and to test whether the data fit the hypothesised measurement model (refer Figure 1). This study used AMOSv20 to evaluate the final measurement model. The reliability of the various factors ranged from .73 to .94, indicating good internal consistency (Table I). The study assessed convergent validity by computing the average variance extracted (AVE) scores, with the subsequent results showing that all were greater than .50 , thereby indicating acceptable convergent validity. In addition, the average variances extracted for each of the constructs were all greater than their correlations with the other constructs. The results indicate that all the constructs used in the study are distinct measurements, and achieve discriminant validity.

To test for the potential problem of common method bias, Harman's single factor test was used. This test is employed to detect for bias introduced by the survey instrument that results in its scale items loading on a single common factor. Common method bias is signaled if the total variance for a single factor exceeds 50\% (Hatcher, 1994). Subsequent analysis revealed a value of $31.2 \%$, thereby indicating that common method bias does not present a significant threat to this study.

Table I. Internal consistency, square root of average variance extracted and correlation matrix

\begin{tabular}{llccccccccc}
\hline \multirow{2}{*}{ Measurements } & Internal & \multicolumn{1}{c}{ Validity } \\
\cline { 2 - 10 } & Consistency & $\mathbf{1}$ & $\mathbf{2}$ & $\mathbf{3}$ & $\mathbf{4}$ & $\mathbf{5}$ & $\mathbf{6}$ & $\mathbf{7}$ & $\mathbf{8}$ & $\mathbf{9}$ \\
\hline 1 Environmentally & .94 &. $\mathbf{9 2}$ & & & & & & & \\
responsible & & & & & & & & & \\
2 Employee welfare & .94 & .80 & .93 & & & & & & \\
3 Animal welfare & .82 & .89 & .77 & .90 & & & & & \\
4 Slow fashion & .88 & .06 & .13 & .17 & .83 & & & & \\
5 Cost attributes & .81 & .30 & .31 & .34 & .21 & .74 & & & \\
6 Physical attributes & .73 & .31 & .32 & .36 & .44 & .30 & .77 & & \\
7 Extrinsic attributes & .86 & .42 & .42 & .41 & .38 & .09 & .40 & .80 & & \\
8 Overall attitude & .86 & .40 & .42 & .42 & .51 & .05 & .38 & .57 & .89 & \\
9 Purchase intention & .84 & .39 & .43 & .38 & .41 & .11 & .30 & .51 & .88 & .92 \\
\hline
\end{tabular}

The conceptual framework 
Structural equation modeling was employed to test the conceptual framework. All measures of global fit indicate adequate model fit (Table II). It should also be noted that the emphasis of this study is on the relationships between key constructs rather than the measurement model per se. 
Table II. Goodness of Fit Analysis

\begin{tabular}{lclc}
\hline \multicolumn{1}{c}{ Goodness of Fit Measure } & Result & \multicolumn{1}{c}{ Goodness of Fit Measure } & Result \\
\hline Model Fit & & Model Comparison & \\
\cline { 2 - 4 } Chi-squared & 871.461 & Tucker-Lewis Index (TLI) & .95 \\
Degrees of Freedom & 521 & Normed Fit Index (NFI) & .90 \\
P-value & .000 & Comparative Fit Index (CFI) & .95 \\
Cmin/df & 1.673 & & \\
Goodness of Fit Index & .87 & & \\
Adjusted Goodness of Fit & .84 & & \\
RMSEA & .05 & & \\
\hline
\end{tabular}

Table III presents the beta coefficients from the various relationships depicted in the conceptual model. As the results indicate, $\mathrm{H} 2(\beta=.23, \mathrm{t}=4.13, \mathrm{p}<.001), \mathrm{H} 4(\beta=.38, \mathrm{t}=5.28$, $p<.001), H 5(\beta=-0.09, t=-2.10, p<.05), H 6(\beta=.55, t=4.66, p<.001)$ and $H 7(\beta=.38, t=$ $6.07, \mathrm{p}<.001$ ) were all supported. As such, employee-welfare, slow-fashion, cost attributes, physical attributes and extrinsic attributes were all found to influence consumers' overall attitude toward ethical clothing. Moreover, $\mathrm{H} 8(\beta=.93, t=9.73, p<.001)$ was also supported, thereby indicating that overall attitude influences purchase intention.

Table III. Direct effect on the conceptual model

Hypothesis

$\mathrm{H} 1$ : Environmentally response attributes $\rightarrow$ Overall attitude

$\mathrm{H} 2$ : Employee welfare attributes $\rightarrow$ Overall attitude

H3: Animal welfare attributes $\rightarrow$ Overall attitude

$\mathrm{H} 4$ : Slow fashion attributes $\rightarrow$ Overall attitude

$\mathrm{H} 5$ : Cost attributes $\rightarrow$ Overall attitude

H6: Physical attributes $\rightarrow$ Overall attitude

H7: Extrinsic attributes $\rightarrow$ Overall attitude

H8: Overall attitude $\rightarrow$ Purchase intention
Regression Coefficient (t-value)

$.06(1.13)$

$-.0 .93 * 5 * 49.73)$

${ }^{*}=p<.05,{ }^{\star *}=p<.01,{ }^{* \star *}=p<.001$

\section{DISCUSSION}

\section{Theoretical implications}

Research has consistently found that even when buying clothing specifically marketed and labelled as 'ethical', consumers evaluate both its conventional and ethical qualities (Jägel et al., 2012; Koszewska, 2013, Niinimäki, 2010). In fact, when it comes to the final purchase decision, the influence of the former can often outweigh that of the latter (Sneddon et al., 2014). This body of research, however, was limited via its operationalisation of ethical clothing in a way that failed to include all of its dimensions. In the context of the attitudebehaviour gap, this served as a potentially significant oversight. This study therefore sought to revisit consumer attitudes towards ethical clothing using a more inclusive, consumerbased definition.

The two dimensions that exerted the strongest influence on overall attitude were physical and extrinsic attributes. Hence, even with an expanded operationalisation of ethical clothing, conventional dimensions retain their mantle as the determinant factor. This provides further support for the notion that consumers only perceive value in an ethical garment when it 
performs at least as well as its conventional alternative (Meyer, 2001), in which case it can serve to differentiate it (Niinimäki, (2010).

Slow fashion served as the most influential ethical dimension. This is a significant finding because it means that the ethical dimension with the strongest impact on consumer attitudes is also one that is often overlooked by academics when operationalising ethical clothing. This finding adds further support to the notion that durable clothing serves as a key driver behind the purchase of ethical clothing (Jägel et al., 2012).

Employee welfare attributes were also found to share a positive relationship with overall attitude. A likely reason for this is that consumers have become better informed of humanbased ethical issues relating to the clothing industry (Carrington et al., 2010). Such issues have increasingly been of interest to mainstream media due to a combination of the scale of the matter being reported and the involvement of well-known brands (Raciniewska, 2014), with the collapse of the Rana Plaza clothing factory in Bangladesh serving as a prime example (Clean Clothes, 2016). One view holds that humans exhibit stronger levels of sympathy for other humans then they do for either animals or the environment (Loewenstein \& Small, 2007). This in turn has a twofold effect. Firstly, the media is more likely to report on the clothing industry's negative impacts in relation to employee welfare (Achabou \& Dekhili, 2015). This in turn leads to the second effect, which is that as a result, consumers are more likely to be aware of, and care about, employee welfare impacts.

This study also found that the lower the perceived cost associated with purchasing ethical clothing, the more positive the attitude towards it. This finding provides empirical support for the notion that due to its higher price and limited availability, the time, effort and financial cost of buying ethical clothing risks exceeding the perceived benefits of owning it (Beard, 2008). Adding further significance to this finding is the way in which cost was operationalised. Previous research into the influence of cost fell into one of three categories. The first category focused on consumer attitudes to ethical products in general rather than ethical clothing specifically (i.e. Bonini \& Oppenheim, 2008; Laroche et al., 2001; Ottman et al., 2006). The second category typically conceptualised cost purely in terms of price (i.e. Ellis et al., 2012; McGoldrick \& Freeman, 2008; Shen et al., 2012). The third category comprised small sample, qualitative studies that, whilst providing insight into the importance of cost, could not empirically establish its direct association with overall attitude (i.e. Carrigan \& Attalla, 2001; Joergens, 2006; Perry \& Chung, 2016). The empirical confirmation offered by this study that cost, when operationalised in terms of price, time and effort influences consumers' overall attitude, therefore represents an important step forward in the field of ethical clothing.

In contrast, environmentally responsible and animal welfare attributes were found to share no significant relationship with overall attitude. In the case of the former, such a result contradicts the findings from several previous studies (i.e. Gam, 2011; Hwang et al., 2015; Kozar \& Hiller Connell, 2013). A lack of consumer knowledge serves as a likely reason for this unsupported hypothesis because it serves as a key influence on environmental consumerism (Chan, 1999). The hypothesis rested on the assumption that consumers are aware of the negative environmental impacts of the clothing industry and the means by which ethical clothing can help address them. In the absence of these two conditions, there is no logical link between the two. Given that consumers' are largely unaware of the clothing industry's negative environmental impacts (Pookulangara \& Shephard, 2013) it serves as a likely explanation as to why environmental responsibility was found to have a non-significant influence.

A related explanation may lie in the fact that several previous studies utilised student samples (i.e. Gam, 2011; Hwang et al., 2015; Kozar \& Hiller Connell, 2013). Many university degrees include a subject dedicated entirely to ethics or comprise various subjects that 
include ethical content. Logically, this can be expected to have influenced students' ethical knowledge. The significance of this stems from studies showing that such knowledge can positively influence attitudes towards ethical clothing (Kozar \& Hiller, 2013; Shen et al., 2012; Sneddon et al., 2014). The notion that university samples could be biased in favour of ethical products may explain why these findings differ from those of a study that utilised a random sample of the wider consumer population.

The non-significant relationship between animal welfare attributes and overall attitude is likely due to a combination of consumer knowledge and the attitude context. Unlike an attitude context sharing obvious links with animal welfare (e.g. clothing made from wool, fur or leather) the attitude context for this study was casual clothing. Whilst such clothing still has implications for animal welfare (e.g. animal testing, pollution of eco-systems etc.) the extent to which consumers recognise this is dependent on their level of knowledge. When such knowledge is low, consumers are less likely to exhibit positive ethical attitudes and behaviours (Dickson, 2000). Previous studies that have identified a link between animal welfare and consumer decision-making have done so using wool, a context with a more obvious association with animals (i.e. Hustvedt et al. 2008; Peterson et al. 2012). As such, the influence of animal welfare appears to be quite context specific.

These findings, when viewed in an overall sense, also indicate that consumers' overall attitude towards ethical clothing is influenced by multiple motives. For example, because physical and extrinsic attributes are primarily designed to benefit the wearer, it suggests that the purchase of ethical clothing has as much to do with enhancing self-interest as it is does with protecting the environment, employees and animals. This is consistent with the notion that the various forces behind the purchase of ethical clothing can operate in apparent conflict with each other (Hustvedt \& Dickson, 2009).

\section{Practical implications}

As per the results of this study, even in an ethical clothing context, the emphasis of marketing communications should be on the garment's conventional attributes because they serve as its most salient influence. Such a finding is not unique to this study, with previous research consistently reporting that consumers evaluate both the conventional (e.g. brand name, price, style) and ethical qualities of ethical clothing. Given that physical and extrinsic attributes were two of the most influential determinants of consumer attitudes, these should be emphasised when clothing companies are developing and marketing ethical clothing. More specifically, ethical clothing must be comfortable, easy to care for, made by a reputable brand and sold via a retailer with a good reputation.

Of the four dimensions of ethical clothing, only employee welfare and slow fashion attributes were found to influence consumers' attitudes, with the influence of environmental responsibility and animal welfare attributes both found to be non-significant. This one finding has multiple implications. Firstly, it suggests that the promotional activities of manufacturers and retailers should emphasise the employee welfare and slow fashion attributes of an ethical garment. Hence the working conditions of the factories that produced the garment and the fair wages that workers' were paid should be emphasised on websites and clothing labels. Similarly, the garment's hard-wearing traits and fashionable longevity should also serve as a focus of communications. Moreover, given that the purchase of ethical clothing appears to be strongly influenced by self-serving motives, communications should also make clear the 'additional' benefits that purchasing a durable garment has on the environment. This will help address the problem of consumers being unaware that slow fashion offers benefits that extend beyond the wearer (i.e. Gabrielli et al., 2013; Pookulangara \& Shephard, 2013).

Another key implication is that the benefits of the two non-significant dimensions environmental responsibility and animal welfare attributes - also need to be promoted. The 
key focus in this case should be on educating consumers. This should involve highlighting the harm that even casual clothing can have on animals and the environment, and the ways in which ethical clothing helps address this. In doing so, it will help provide the necessary knowledge consumers need in order to make effective ethical clothing decisions.

Cost attributes were also found to play an important role in forming consumers' attitudes towards ethical clothing. More specifically, as the cost of purchasing ethical clothing increases, consumers' overall attitude towards it becomes less positive. Cost in this context refers to purchase barriers, and therefore extends beyond its layman's meaning of price to incorporate other obstacles such as the time and effort required to find and acquire it. The fact that it served as a salient influence therefore demonstrates that marketing activities designed to encourage the purchase of ethical clothing must go beyond simply reducing its price. This should include making ethical clothing more accessible via a number of distribution channels. While this might suggest increasing the number of bricks-and-mortar stores from which it is sold, such a solution may be impractical. This is because retail stores have finite selling space, and may therefore be hesitant to allocate some proportion of that space to a fashion category that still largely serves as a niche market. In contrast, online selling would suffer from no such limitation. Moreover, given the virtual retail environment that online selling represents, it largely nullifies the temporal and spatial costs associated with bricks-and-mortar shopping. Most importantly, selling ethical clothing via websites offers the additional benefit of being able to provide the sort of detailed information required to address consumers' lack of knowledge about ethical clothing.

\section{Limitations and future research}

There are two key limitations to be considered when interpreting the results from this study. The first relates to slow fashion. Due to the desire to avoid biasing responses, and consistent with qualitative findings (i.e. Gabrielli et al., 2013; Jägel et al., 2012; Kim et al., 2013), it was operationalised using a more neutral theme revolving around durability. When measured in this manner, this study found that slow fashion served as one of the more salient influences of consumer attitudes towards ethical clothing. It should be acknowledged though that this operationalisation could also have resulted in respondents perceiving it as more of a conventional construct than an ethical one. In theory, consumer demand for slow fashion should derive from consumer knowledge of its positive ethical implications (Pookulangara \& Shephard, 2013). However, the mere durability of a garment, on its own, may be sufficient to shape consumer attitudes, irrespective of the ramifications such durability has for the environment. If so, despite its academic classification as an ethical dimension, consumers may have perceived it as a quality-oriented conventional dimension. As such, whilst slow fashion offers ethical benefits, its' purchase may not be ethically motivated. In a study seeking to measure the influence of ethical attributes relative to that of conventional ones, the inability to decisively gauge which of these two categories respondents associated the benefits of slow fashion with, must be considered a limitation.

The second limitation stems from the measurement of animal welfare attributes using casual clothing as the attitude context. This choice of context may have biased the subsequent results by understating the importance of this dimension. More specifically, whilst there is a logical link between animal welfare and fur-, leather- and/or pelt-based clothing, for the layperson, such a link is likely to be far less obvious in the case of casual clothing. Given that the findings from this study suggest that consumer attitudes towards ethical clothing may be context specific, future research should seek to measure the same seven constructs using different attitude contexts.

\section{REFERENCE LIST}

Abraham-Murali, L., and Littrell, M. (1995), "Consumer's Conceptualization of Apparel Attributes", Clothing and Textiles Research Journal, Vol. 13 No. 2, pp. 65-74. 
Achabou, M., \& Dekhili, S. (2015), "Constraints and Drivers of Growth in the Ethical Fashion Sector: The Case of France", Sustainable Fashion Supply Chain Management, Vol. 1, pp. 167-181.

Afrin, T., Tsuzuki, T., and Wang, X. (2009), "Bamboo fibres and their unique properties". Paper presented at the Natural fibres in Australasia: proceedings of the combined (NZ and AUS) Conference of The Textile Institute, Dunedin 15-17th April 2009.

Auger, P., Burke, P., Devinney, T., and Louviere, J. (2003), "What Will Consumers Pay for Social Product Features?", Journal of Business Ethics, Vol. 42 No. 3, pp. 281-304.

Australian Bureau of Statistics. (2011), Population by Age and Sex, Regions of Australia, 2011. Retrieved from:

http://www.abs.gov.au/ausstats/abs@.nsf/Products/3235.0 2011 Main+Features Victoria\# PARALINK6, Last accessed: February $2^{\text {nd }} 2016$.

Beard, N. (2008), "The Branding of Ethical Fashion and the Consumer: A Luxury Niche or Mass-market Reality?" Fashion Theory: The Journal of Dress, Body \& Culture, Vol. 12 No. 4, pp. 447-467.

Bonini, S., and Oppenheim, J. (2008), "Cultivating the green consumer", Stanford Social Innovation Review, Vol. 6 No. 4, pp. 56-61.

Bray, J., Johns, N., and Kilburn, D. (2011), "An Exploratory Study into the Factors Impeding Ethical Consumption”, Journal of Business Ethics, Vol. 98 No. 4, pp. 597-608.

Carrigan, M., and Attalla, A. (2001), "The myth of the ethical consumer - do ethics matter in purchase behaviour”, Journal of Consumer Marketing, Vol. 18 No. 7, pp. 560-577.

Carrington, M., Neville, B., and Whitwell, G. (2010), "Why Ethical Consumers Don't Walk Their Talk: Towards a Framework for Understanding the Gap Between the Ethical Purchase Intentions and Actual Buying Behaviour of Ethically Minded Consumers", Journal of Business Ethics, Vol. 97 No. 1, pp. 139-158.

Chan, T-Y., and Wong, C. (2012), "The consumption side of sustainable fashion supply chain: Understanding fashion consumer eco-fashion consumption decision", Journal of Fashion Marketing and Management, Vol. 16, No. 2, pp. 193-215.

Choose Cruelty Free. (2014), Winter News 2014, Retrieved from http://www.choosecrueltyfree.org.au/wp-content/uploads/2015/04/CCF-News-Winter2014.pdf, Last accessed: August $12^{\text {th }} 2016$.

Crowley, S., and Fan, X. (1997), "Structural equation modeling: basic concepts and applications in personality assessment research", Journal of Personality Assessment, Vol. 68 No. 3, pp. 508-531.

Dickson, M. (2000), "Personal Values, Beliefs, Knowledge, and Attitudes Relating to Intentions to Purchase Apparel from Socially Responsible Businesses", Clothing and Textiles Research Journal, Vol. 18 No. 1, pp. 19-30.

Dickson, M., Eckman, M., and Loker, S. (2009), Social responsibility in the global apparel industry, Fairchild Books, New York, USA.

Ellis, J., McCracken, V., and Skuza, N. (2012), "Insights into willingness to pay for organic 
cotton apparel", Journal of Fashion Marketing and Management, Vol. 16 No. 3, pp. 290-305.

Forney, J., Park, E., and Brandon, L. (2005), "Effects of evaluative criteria on fashion brand extension”, Journal of Fashion Marketing and Management, Vol. 9 No. 1, pp. 156-165.

Gabrielli, V., Baghi, I., and Codeluppi, V. (2013), "Consumption practices of fast fashion products: a consumer-based approach", Journal of Fashion Marketing and Management, Vol. 17 No. 2, pp. 206-224.

Gam, H. (2011), "Are fashion-conscious consumers more likely to adopt eco-friendly clothing?", Journal of Fashion Marketing and Management, Vol. 15 No. 2, pp. 178-193.

Gam, H., Ma, Y., and Banning, J. (2014), "Socially Responsible Apparel Labels: Effects on Fashionable Shoppers", Family and Consumer Sciences Research Journal, Vol. 42 No. 3, pp. 292-305.

Gorsuch, R. (1997), "Exploratory factor analysis: its role in item analysis", Journal of Personality Assessment, Vol. 68 No 3, pp. 532-560.

Goworek, H. (2011), "Social and environmental sustainability in the clothing industry: a case study of a Fair Trade retailer", Social Responsibility Journal, Vol. 7 No. 1, pp. 74-86.

Hair, J., Black, B., Babin, B., and Anderson, R. (2010). Multivariate Data Analysis, $7^{\text {th }}$ edition, Pearson Prentice Hall, New Jersey USA.

Hansen, E., and Schaltegger, S. (2013), "100 per cent organic? A sustainable entrepreneurship perspective on the diffusion of organic clothing", Corporate Governance, Vol. 13, No. 5, pp. 583-598.

Harman, H. (1976), Modern Factor Analysis, University of Chicago Press, Chicago, USA.

Hatcher, L. (1994), A Step-By-Step Approach to Using the SAS System for Factor Analysis and Structural Equation Modeling, SAS Institute, Cary, USA.

Holland, S. (2015), Women and Spending. Last accessed: April $7^{\text {th }}$, 2016. Retrieved from: http://sheconomy.com/report/marketing-to-women-quick-facts

Hustvedt, G., and Dickson, M. (2009), "Consumer likelihood of purchasing organic cotton apparel: Influence of attitudes and self-identity", Journal of Fashion Marketing and Management, Vol. 13 No. 1, pp. 49-65.

Hustvedt, G., Peterson, H., and Chen, Y-J. (2008), "Labeling wool products for animal welfare and environmental impact", International Journal of Consumer Studies, Vol. 32 No. 5, pp. 427-437.

Hwang, C., Lee, Y-A., and Diddi, S. (2015), "Generation Y's moral obligation and purchase intentions for organic, fair-trade, and recycled apparel products", International Journal of Fashion Design, Technology and Education, Vol. 8 No. 2, pp. 97-107.

Hyllegard, K., Ogle, J., and Yan, R-N. (2009), "The impact of advertising message strategy fair labour v. sexual appeal - upon Gen Y consumers' intent to patronize an apparel retailer", Journal of Fashion Marketing and Management, Vol. 13 No. 1, pp. 109-127.

Jägel, T., Keeling, K., Reppel, A., and Gruber, T. (2012), "Individual values and motivational complexities in ethical clothing consumption: A means-end approach", Journal of Marketing 
Management, Vol. 28 No. 3/4, pp. 373-396.

Jegethesan, K., Sneddon, J., and Soutar, G. (2012), “Young Australian consumers' preferences for fashion apparel attributes", Journal of Fashion Marketing and Management, Vol. 16 No. 3, pp. 275-289.

Jin, B., Park, J., and Ryu, J. (2010), "Comparison of Chinese and Indian consumers' evaluative criteria when selecting denim jeans; A conjoint analysis", Journal of Fashion Marketing and Management, Vol. 14 No. 1, pp. 180-194.

Joergens, C. (2006), "Ethical fashion: myth or future trend?", Journal of Fashion Marketing and Management, Vol. 10 No. 3, pp. 360-371.

Joy, A., Sherry, J., Venkatesh, A., Wang, J., and Chan, R. (2012), "Fast Fashion, Sustainability, and the Ethical Appeal of Luxury Brands", Fashion Theory: The Journal of Dress, Body \& Culture, Vol. 16 No. 3, pp. 273-296.

Jung, S., and Jin, B. (2014), "A theoretical investigation of slow fashion: sustainable future of the apparel industry", International Journal of Consumer Studies, Vol. 38 No. 5, pp. 510-519.

Kim, H., Ho Jung, C., and Yoon, N. (2013), "The motivational drivers of fast fashion avoidance", Journal of Fashion Marketing and Management, Vol. 17 No. 2, pp. 243-260.

Kim, H-S., and Damhorst, M. (1998), "Environmental Concern and Apparel Consumption", Clothing and Textiles Research Journal, Vol. 16 No. 3, pp. 126-133.

Kim, H-S., Damhorst, M., and Lee, K-H. (2002), "Apparel involvement and advertisement processing: A model", Journal of Fashion Marketing and Management, Vol. 6 No. 3, pp. 277302.

Kollmuss, A., and Agyeman, J. (2002), "Mind the Gap: Why do people act environmentally and what are the barriers to pro-environmental behavior?", Environmental Education Research, Vol. 8 No. 3, pp. 239-260.

Koszewska, M. (2013), "A typology of Polish consumers and their behaviours in the market for sustainable textiles and clothing", International Journal of Consumer Studies, Vol. 37 No. 5 , pp. 507-521.

Kozar, J., and Hiller Connell, K. (2013), "Socially and environmentally responsible apparel consumption: knowledge, attitudes, and behaviors", Social Responsibility Journal, Vol. 9 No. 2, pp. 315-324.

Laroche, M., Bergeron, J., and Barbaro-Forleo, G. (2001), "Targeting consumers who are willing to pay more for environmentally friendly products", Journal of Consumer Marketing, Vol. 18 No. 6, pp. 503-520.

Larsen, S., Hansen, J., Knudsen, H., Wenzel, H., Larsen, H., \& Kristensen, F. (2007). EDIPTEX - Environmental assessment of textiles. Danish Ministry of the Environment, Environmental Protection Agency, Working Report No. 24. Available at: orbit.dtu.dk/files/7635219/EDIPTEX.pdf. Last accessed: June 8, 2017.

MacCarthy, B. and Jayarathne, P. (2011), "Sustainable collaborative supply networks in the international clothing industry: a comparative analysis of two retailers", Production Planning \& Control, Vol. 23 No. 4, pp. 252-268. 
McGoldrick, P., and Freestone, O. (2008), "Ethical product premiums: antecedents and extent of consumers' willingness to pay", The International Review of Retail, Distribution and Consumer Research, Vol. 18 No. 2, pp. 185-201.

Meyer, A. (2001), "What's in it for the customers? Successfully marketing green clothes", Business Strategy and the Environment, Vol. 10 No. 5, pp. 317-330.

Moon, K., Youn, C., Chang, J., and Yeung, A. (2013), "Product design scenarios for energy saving: A case study of fashion apparel", International Journal of Production Economics, Vol. 146 No. 2, pp. 392-401.

NASA. (2013), The current and future consequences of global change. Retrieved from http://climate.nasa.gov/effects. Last accessed: September $10^{\text {th }} 2016$,

Niinimäki, K. (2010), "Eco-clothing, consumer identity and ideology", Sustainable Development, Vol. 18 No. 3, pp. 150-162.

Ogle, J., Hyllegard, K., and Yan, R-N. (2014), "An investigation of mothers' and tween daughters' clothing preferences and purchase intentions toward a prosocial clothing company", Journal of Fashion Marketing and Management, Vol. 18 No. 1, pp. 70-84.

Ottman. J., Stafford. E., and Hartman, C. (2006), "Avoiding Green Marketing Myopia: Ways to Improve Consumer Appeal for Environmentally Preferable Products", Environment: Science and Policy for Sustainable Development, Vol. 48 No. 5, pp. 22-36.

Oxford Dictionary. (2017), Casual clothing. Retrieved 14 February, from https://en.oxforddictionaries.com/definition/casual

Peterson, H., Hustvedt, G., and Chen, Y-J. (2012), "Consumer Preferences for Sustainable Wool Products in the United States", Clothing and Textiles Research Journal, Vol. 30 No. 1, pp. 35-50.

Perry, A., and Chung, T. (2016), "Understand attitude-behaviour gaps and benefit-behaviour connections in eco-apparel", Journal of Fashion Marketing and Management, Vol. 20 No. 1, pp. 105-119.

Pookulangara, S., and Shephard, A. (2013), "Slow fashion movement: Understanding consumer perceptions - An exploratory study", Journal of Retailing and Consumer Services, Vol. 20 No. 2, pp. 200-206.

Rahman, O., Zhu, X., and Liu, W-S. (2008), „A study of the pyjamas purchasing behaviour of Chinese consumers in Hangzhou, China", Journal of Fashion Marketing and Management, Vol. 12 No. 2, pp. 217-231.

Reimers, V., Magnuson, B., and Chao, F. (2016),"The academic conceptualisation of ethical clothing", Journal of Fashion Marketing and Management, Vol. 20 No. 4, pp. 383-399.

Saicheua, V., Knox, A., and Cooper, T. (2012), "Sustainability in clothing supply chainimplications for marketing". In: Proceedings of the 37th Annual Macromarketing Conference, Berlin, Germany, June 13th-16th 2012. Last accessed: June $8^{\text {th }}$, 2017. Available at: http://citeseerx.ist.psu.edu/viewdoc/download;jsessionid=FD111B5DD1A55DBF04C9F8E29 5DC2463?doi=10.1.1.470.3942\&rep=rep1\&type=pdf, pp. 284-307.

Scaturro, S. (2008), "Eco-tech Fashion: Rationalizing Technology in Sustainable Fashion", Fashion Theory: The Journal of Dress, Body \& Culture, Vol. 12, No. 4, pp. 469-488. 
Seiders, K., Voss, G., Godfrey, A., and Grewal, D. (2007), "SERVCON: development and validation of a multidimensional service convenience scale", Journal of the Academy of Marketing Science, Vol. 35 No. 1, pp. 144-156.

Shen, B., Wang, Y., Lo, C., and Shum, M. (2012), "The impact of ethical fashion on consumer purchase behavior", Journal of Fashion Marketing and Management, Vol. 16 No. 2, pp. 234-245.

Sneddon, J., Soutar, G., and Lee, J. (2014), "Exploring wool apparel consumers' ethical concerns and preferences", Journal of Fashion Marketing and Management, Vol. 18 No. 2, pp. 169-186.

Swinker, M., and Hines, J. (2006), "Understanding consumers' perception of clothing quality: a multidimensional approach", International Journal of Consumer Studies, Vol. 30 No. 2, pp. 218-223.

Taylor, S., and Cosenza, R. (2002), "Profiling later aged female teens: mall shopping behavior and clothing choice", Journal of Consumer Marketing, Vol. 19 No. 5, pp. 393-408.

Watson, M., and Yan, R-N. (2013), "An exploratory study of the decision processes of fast versus slow fashion consumers", Journal of Fashion Marketing and Management, Vol. 17 No. 2, pp. 141-159.

Zhang, Z., Li, Y., Gong, C., and Wu, H. (2002), "Casual wear product attributes: A Chinese consumers' perspective", Journal of Fashion Marketing and Management, Vol. 6 No. 1, pp. 53-62. 


\section{APPENDIX 1: Scale items}

\section{Environmentally responsible attributes}

- The materials used were produced without the use of pesticides.

- The byproducts from making the clothing (e.g. emissions, wastewater) were not released into the air or waterways.

- It was made in the most efficient way possible (e.g. using less water \& electricity).

- At least some part of the shirt was made using recycled materials (e.g. the tags).

\section{Employee welfare attributes}

- The people who made it were paid a fair wage for their work.

- It was made by people working in safe working conditions.

- It was not made using child labour.

- It was not made in a sweatshop.

\section{Animal welfare attributes}

- It is not made out of animal fur, pelts or leather.

- Dyes and bleaches used to make the clothing were not tested on animals.

- The by-products of making the clothing (e.g. waste water) were managed so that they posed no threat to wildlife (e.g. fish, birds etc.).

\section{Cost attributes}

- Because it contains all the features just listed, it is about $25 \%$ more expensive than more 'conventional' garments.

- It takes approximately 25 minutes driving time (or public transport commute) to reach the nearest store selling this type of garment.

- Because this sort of garment isn't widely available, extra time and effort is required to identify stores that sell it.

- In general, buying this type of garment is not as convenient as buying a more 'conventional' garment.

\section{Slow fashion attributes}

- It doesn't stretch or lose shape after only a few washes.

- It will continue to be fashionable for more than one season.

- It can be worn for at least a few seasons without falling apart.

- It is an item that you would want to wear for multiple seasons.

Physical attributes

- It comes in a range of colours.

- It is comfortable to wear.

- It is easy to care for and wash.

- It is made from your preferred fabric.

Extrinsic attributes

- The company that made the garment has a good reputation.

- The store that sells the garment has a good reputation.

- The country that made the garment has a good reputation for making high quality goods.

- The overall image of the garment is a positive one. 